\title{
LA AGONÍA DE LA CREATIVIDAD \\ REPRESENTACIONES DE LO APOCALÍPTICO \\ EN DAY OF THE DEAD DE GEORGE A. ROMERO
}

\author{
The Agony of Creativity \\ Representations of the Apocalyptic \\ In Day of the Dead by George A. Romero
}

Emiliano Aldegani
(UNMDP, Argentina)

\begin{abstract}
Resumen
El presente trabajo se propone recuperar algunas notas particulares del cine de G. A. Romero en relación a su representación del derrumbe del sistema social, con el fin de explorar su potencial crítico para denunciar los excesos e inconsistencias del imaginario capitalista y de la sociedad de consumo. Es decir, observar el modo en el que distintos elementos son presentados en el ámbito de la ciencia ficción, y el paralelo que establecen con algunos diagnósticos de las ciencias sociales, y en particular de la filosofía, sobre la crisis cultural que experimentan las sociedades occidentales a partir del debilitamiento de sus instituciones centrales.

Para ello el trabajo abordará la perspectiva que presenta el cine de Romero determinado agotamiento del mundo, expresado bajo la metáfora del apocalipsis zombi, en particular, en el contraste que se ofrece entre dos imágenes que se presentan en las primeras escenas de su film Day of the Dead (1985). A su vez, recuperando la conceptualización de la figura del zombi que se ha establecido recientemente en diferentes ensayos críticos, el trabajo busca recuperar la relevancia que la mimesis, como conducta social, manifiesta en la caracterización del zombi romeriano y la centralidad de este aspecto en relación a los fenómenos sociales a los que su cine se asocia.

Las corrientes de filosofía crítica que se recuperarán se identifican principalmente con el diagnóstico que estableciera tempranamente la filosofía de Friedrich Nietzsche en sus observaciones sobre la historia y la dificultad de las sociedades occidentales para generar cultura, y a partir de esta lectura, se recuperarán también los aportes teóricos de Cornelius Castoriadis y del el filósofo sur coreano Byung-Chul Han.
\end{abstract}

Palabras clave: Romero | Cine | Day of the Dead | Filosofía | Sociedad de consumo.

\begin{abstract}
By means of this work I aim at recovering some peculiar notes of the cinema of George Romero dealing with his representation of the falling of the social system. This task will allow us to explore his critical potential, that reveals the excess and the inconsistencies of consumerism and capitalist imaginaries. In other words, I aim at observing the means by which different aspects presented in a sciencefiction environment can be compared to some proposals offered by social human sciences, particularly by philosophy, on the cultural crisis in Western societies because of the gradual weakening of their main institutions.
\end{abstract}


I will consider Romero's approach to certain exhaustion of the world, expressed by means of the metaphor of the zombie apocalypse, particularly in the contrast between two images of the first scenes of the film Day of the Dead (1985). On the basis of the recovery of the concept of zombie that has been appearing in recent critical essays, I aim at also recovering the relevance that mimesis, as social behavior, makes manifest in the characterization of Romero's zombie and the importance of this aspect in relation to some social phenomena connected to his cinema.

The trends in critical philosophy that will be reconsidered here are identified mainly with the early evaluation of philosophy developed by Friedrich Nietzsche in his observations about history and Western societies difficulty for creating culture. On the basis of this interpretation, the theoretical contributions made by Cornelius Castoriadis and Byung-Chul Han will be also reconsidered.

Keywords: Romero | Cinema | Day of the Dead | Philosophy | Consumerism.

\section{Introducción:}

El presente trabajo se propone recuperar algunas notas particulares del cine de G. A. Romero en relación a su representación del derrumbe del sistema social y la crisis de las relaciones sociales, con el fin de explorar su potencial crítico para denunciar los excesos y las inconsistencias del imaginario capitalista y de la sociedad de consumo. Es decir, observar el modo en el que distintos elementos son presentados en el ámbito de la ciencia ficción, y el paralelo que establecen con algunos diagnósticos de las ciencias sociales, y en particular de la filosofía, sobre la crisis cultural que experimentan las sociedades occidentales a partir del debilitamiento de sus instituciones centrales. Para ello el trabajo abordará la perspectiva que presenta el cine de Romero desde de la década del setenta sobre un cierto agotamiento del mundo, expresado bajo la metáfora del apocalipsis zombi, y su vínculo con los fenómenos sociales que denuncia.

Ciertamente, el interés en recuperar el sentido crítico del cine de Romero se ve estimulado en la actualidad por la proliferación de distintas expresiones culturales tanto en la esfera del cine como de las series de televisión, la literatura, la historieta y los video juegos, que se adscriben a la temática, a la vez que en el impacto y la recepción de estos productos. Y en particular, por la reciente publicación de diferentes ensayos que buscan recuperar el potencial de la figura del zombi como una metáfora que pueda reflejar algunas características centrales de la cultura norteamericana y de las tendencias que ésta promueve en occidente. (Coulombe, 2012; Fernández, 2011; Lucena, 2012; Paris, 2013).

En efecto, la temática zombi atraviesa una gran variedad de espacios y discursos que no son fácilmente abordables por una perspectiva común, en tanto que mezclan elementos vinculados al lenguaje audiovisual, a distintas formas de iconografía mítica, a dinámicas particulares que se expresan en diferentes videojuegos, e inclusive al traducirse en reglamentos específicos en la enorme cantidad de juegos de mesa o de rol, eventos sociales como las Zombie Walk, etc. Eso sin detenerse en las diferentes variables específicas que presentan sus representaciones audiovisuales a partir de su incorporación al mundo publicitario, la creación de plataformas audiovisuales complejas que interactúan con objetos reales como el advergame Zombies and Skittles (2009), o lenguaje particular del video clip musical. Estas posibilidades son estimuladas a su vez por la facilidad que ofrece la temática para incorporarse a cualquier lenguaje o tópico preexistente, como se observa en la novela Pride and Prejudice and Zombies (2009) de Seth Grahame-Smith, en las adaptaciones como Marvel Zombies (2006) de Robert Kirkman, o la publicación del Call of Duty: Zombies (2009) de Activision.

Atendiendo a esta dificultad el presente trabajo se centrará en el contraste que ofrecen 
dos imágenes extraídas, como se adelanta en el título, del film Day of the Dead (1985) de Romero. Este abordaje, sin embargo, busca ser inclusivo de gran parte de las expresiones actuales de la temática, pues la mayor parte de los productos relativos a la figura del zombi son subsidiarios en mayor o menor medida de la representación romeriana del zombi, concretamente, de los rasgos particulares que presenta la figura del zombi a partir de su aparición en el film The night of the living Dead (1968).

Como destaca el filósofo canadiense Maxime Coulombe, el vínculo entre el universo simbólico del zombi y el apocalipsis, como final irreversible del mundo conocido, no surge sino hasta la representación romeriana del muerto viviente. Representaciones anteriores como las del mito haitiano, en sus diferentes variantes, se asocian para el autor principalmente al imaginario de la esclavitud, en la medida que el zombi es privado de su voluntad por la acción de un fármaco, y a su vez, al imaginario de la emancipación, en tanto que de no subministrársele el fármaco por determinado tiempo, la persona podría liberarse del maleficio (Coulombe, 2012: 24). Aunque esto último no se presenta de la misma forma en todas las formulaciones del mito. La construcción del zombi como un muerto viviente, caníbal y capaz de reproducirse mediante el contagio, no surge sino hasta la caracterización que Romero establece del zombi, y que parece ofrecer un gran potencial para pensarlo como un personaje conceptual que pueda expresar el sentido de la sociedad de consumo. Por lo que incluso cuando los muertos vivientes del cine de Romero mantienen un vínculo con el mito haitiano, los significados a los que se asocian ambas figuras remiten a universos simbólicos claramente diferenciados.

Como se verá a continuación estos elementos se expresan de diferentes maneras en la representación del apocalipsis que presenta el cine de Romero, y en particular en el contraste que se genera entre dos imágenes que se ofrecen en los primeros minutos de la película señalada. La primera correspondiente a una fotografía de un paisaje rural que se encuentra en un almanaque en el sueño de uno de los protagonistas con el que inicia el film. Y la segunda, correspondiente a la imagen de una ciudad totalmente transformada por la infección zombi que es representada a escasos minutos de la primera escena.

El trabajo procederá a señalar el potencial crítico de ambas imágenes, a la vez que a establecer una lectura de los sentidos a los que pueden asociarse, a partir del diagnóstico de distintas corrientes intelectuales sobre el estado de las sociedades actuales, la crisis que presentan los vínculos sociales, y en particular el agotamiento de una forma de institución del campo social sobre su propia estructura (Castoriadis, 2008; Han, 2015b).

En vistas al establecimiento de éste tipo de análisis de recuperarán nociones de diferentes autores, sin atender en detalle las controversias que se han generado entre estos enfoques, pues el objetivo del trabajo es observar el potencial crítico de estas imágenes y su capacidad para entrar en diálogo con distintas formas de teoría crítica, antes que establecer un diagnóstico sobre la actualidad, o sobre la crisis efectiva que atraviesa a las instituciones sociales.

La hipótesis que orienta la lectura de las imágenes será en este sentido la posibilidad de recuperar en la metáfora que ofrece el apocalipsis romeriano, la perspectiva de un agotamiento de las sociedades occidentales sobre su propia estructura, que termina por atentar contra su propia posibilidad de estructurarse como sociedad, y de auto-instituirse a partir de la emergencia de nuevos productos culturales. Y a su vez, la identificación de esta forma de agotamiento con la imposición de la mímesis como conducta social y el modo en que ésta conducta confronta la capacidad creativa del cuerpo social.

Las corrientes de filosofía crítica que se recuperarán en este sentido se identifican principalmente con el diagnóstico que estableciera tempranamente la filosofía de Friedrich Nietzsche en sus observaciones sobre la historia y la dificultad de las sociedades occidentales para generar cultura. Y a partir de esta lectura, se recuperarán también los aportes teóricos de Cornelius Castoriadis y del el filósofo sur coreano Byung-Chul Han. A 
la vez que se recuperarán algunos aportes al análisis específico de la temática zombi ofrecidos por autores como Jorge Fernández Gonzalo, Vincent Paris, Maxime Coulombe y Jorge Matínez Lucena.

\section{Agonía de la creatividad:}

Una primera aproximación desde filosofía al universo simbólico del apocalipsis romeriano puede establecerse a partir de las ideas de Nietzsche sobre la devastación, o en general, sobre la crisis de las sociedades occidentales y su dificultad para generar productos culturales. La perspectiva nietzscheana del estado de la cultura no se inscribe ciertamente en un diagnóstico apocalíptico de su presente, pero ofrece no obstante una lectura del estado cultural de la modernidad que consta de varios elementos que pueden percibirse en la perspectiva que construye Romero de la cultura norteamericana.

En efecto, el conflicto entre la tendencia del cuerpo social a la repetición institucional y su posibilidad de romper el marco simbólico en el que se organiza a partir de la expresión de su capacidad creativa, puede percibirse con gran claridad en la crítica que Nietzsche estableciera a la sociedad moderna, pues el eje principal de su argumentación gira en torno a la carga que lo histórico representa para la producción de lo cultural, y en la imposibilidad de la cultura moderna para superar el peso de su propia historicidad y producirse nuevamente. Nietzsche observa el estado de fragmentación cultural que es producido por el avance del pensamiento científico, y la ruptura con las estructuras míticas que daba un grado de cohesión y unidad al marco cultural en el que los hombres despliegan sus actividades, e identifica esta actitud con lo que denominará como nihilismo consumado. Un estado en el que la cultura no logra producir nuevos símbolos, y cae en una etapa de decadencia. Siguiendo la lectura de David Puche Díaz, "Nietzsche encuentra en la cultura tardomoderna la hegemonía de un tipo de hombre que conduce al estancamiento de la historia. Un hombre improductivo en términos simbólicos, culturales, políticos." (Díaz, 2010: 29). Es precisamente esta fractura del mundo cultural moderno lo que dará paso a aquello que Nietzsche denomina en oportunidades como la devastación o el crecimiento del desierto. Es decir, el arribo del mundo cultural moderno a un estado de desintegración en el que "se ha dejado de crear, de ensayar posibilidades nuevas," (Díaz, 2010: 33) y este fenómeno se produce en tanto que la modernidad se piensa como cercana a un fin de la historia, a un momento de conclusión, pero también por el descreimiento que el nihilismo consumado genera sobre el horizonte de sentido de la modernidad.

En efecto, Nietzsche describe el escenario productivo que ofrece la cultura como un marco de sentido, es decir, como la existencia de un mundo unificado para los individuos. Aquello que la ruptura con el pensamiento mítico deja fracturado y que los procesos de secularización y el avance del pensamiento científico no hacen sino agravar. Lo hombres no pueden producir cultura, en tanto que no pueden producir una unidad de las representaciones y significaciones asociadas a su mundo.

En consonancia con estas ideas, filósofos contemporáneos como Byung-Chul Han, proponen que la excesiva producción de datos que existe en la actualidad, termina por desarticular los mecanismos básicos de remisión que permiten a los símbolos generar sentido. Al igual que Nietzsche, Han advierte que la gramática de lo mítico con su componente centralmente narrativo, es confrontada en la ilustración por la proliferación de datos objetivos y el apoyo en una forma determinada de racionalidad. Pero esta primera ilustración, racional e intuitiva, que Han identifica con la emergencia de la sociedad disciplinaria y que termina por mitificar la validez del análisis cuantitativo, es sucedida por una segunda ilustración, digital, que se caracteriza por la proliferación de cúmulos de datos desarticulados que son inaccesibles a la intuición (Han, 2015d: 88). 
El acceso de los hombres a su actualidad, se ve obstaculizado en la era digital por la excesiva fragmentación de la experiencia en la que todo se transforma en información desarticulada. De este modo, Han afirma que frente al carácter esencialmente narrativo y formativo del pensamiento mítico, he incluso del pensamiento teórico que busca establecer causalidades, emerge una nueva forma de acceso a lo real que se limitan a corroborar equivalencias entre grandes flujos de información. Tanto el discurso narrativo como el discurso causal "ponen el mundo en forma. Dan un curso a las cosas y lo enmarcan, para que estas no se desborden. En cambio, la masa actual de información ejerce un efecto deformativo." La constante fragmentación de la experiencia social en datos desarticulados confronta con la posibilidad de producir experiencias colectivas y significativas. "La tremenda cantidad de información eleva masivamente la entropía del mundo, y también su nivel de ruido." (Han, 2015b: 75)

Cabe observar que la metáfora romeriana no ofrece la imagen de un complejo mundo digital en el que la emergencia desbordante de información anule la posibilidad de lo individuos para establecer una perspectiva común, pues el avance de la infección conduce a los sobrevivientes a una forma de vida gradualmente más rudimentaria. Sin embargo, no es el mundo devastado de Romero aquel que muestra un exceso de información, sino que es la forma específica de la subjetividad que el zombi expresa y la captación que logra hacerse del mundo lo que coincide con el análisis de Han. Pues el mundo que el zombi experimenta no es un mundo causal ni narrativo, sino un mundo conformado a partir de imágenes y situaciones desarticuladas que se organizan parcialmente a partir de un impulso afectivo.

La toma de control de las acciones por parte de la emotividad es precisamente una de las notas que Han señala como estrategia del capitalismo actual. Frente al discurso causal, razonado y argumentativo necesario para un accionar reflexivo y para poder establecer un debate público, el énfasis en lo emocional que preconiza el sistema capitalista busca superar las limitaciones de la racionalidad frente al carácter estrictamente performativo de lo emocional. "Ser libre - afirma - significa incluso dejar paso libre a las emociones. El capitalismo de la emoción se sirve de la libertad. [...] La técnica de poder neoliberal explota esta subjetividad libre" (Han, 2015d: 71). El zombi, en tanto se ha sustraído de la coerción de lo narrativo y del sentido para guiarse exclusivamente por un impulso emocional, es el representante privilegiado de esta perspectiva desarticulada del mundo. El impulso que anima sus acciones no puede identificarse con algo instintivo en la medida que la ingesta de la carne no tiene en su conducta ninguna relación con la nutrición o con la subsistencia. $\mathrm{Su}$ deseo de alimentarse responde a una necesidad tan vacía como ilimitada, y en ese sentido expresa la tendencia irreflexiva a la adquisición de objetos superfluos que promueve el capitalismo de las sociedades de consumo y el discurso publicitario. A su vez, este énfasis en lo emocional se muestra más adecuado a las reacciones espontaneas que requiere la aceleración y la fugacidad de la información, pero retrotrae a los individuos a una continua expectación de la realidad.

A esta situación hace también referencia Castoriadis cuando se refiere a partir de la década del setenta a una pérdida del horizonte común para los hombres (Castoriadis y Lasch, 2013:18). La temporalidad común, los elementos que componen una unidad narrativa de la experiencia se fragmentan, las causas comunes se sectorizan, los reclamos no logran erigirse como contestaciones capaces de proyectar un nuevo proyecto de sociedad sino que suscriben a aspectos cada vez más puntuales. La falta de una perspectiva de conjunto que permita producir colectivamente nuevos fenómenos sociales es lo que llevará a Castoriadis a hablar de un avance de lo insignificante. Los grupos sociales no logran superar la repetición institucional para hacer emerger dentro de sí nuevas significaciones que no sean el mero reflejo de su propio marco simbólico. No es sólo el peso de lo histórico, o de la tradición cultural lo que obstaculiza la emergencia de lo nuevo, sino 
la centralidad que la mímesis ocupa en la conducta de los individuos, que se expresa como repetición, como ritualización de las instituciones. Las sociedades se fragmentan a partir de una repetición de lo aprendido por parte de los individuos que confronta su potencial creativo. Este fenómeno genera un obstáculo a la posibilidad establecer una relación de autonomía social, es decir, de la posibilidad de los hombres de auto-instituirse en la creación de nuevas significaciones y normas. La conservación estática del marco institucional termina por generar un marco de heteronomía para los individuos y un tipo antropológico incapaz de generar cultura (Castoriadis, 2006a; Sartre, 2004).

Está descripción de la crisis de las sociedades occidentales parece encontrar algunos paralelos notables en el cine de Romero, en particular en el hecho de que la infección zombi, al erigirse como el fin del mundo social, constituye un enemigo marcadamente débil frente a otras formas de apocalipsis (Coulombe, 2012: 33). No se trata de una catástrofe natural, o de la emergencia de un enemigo poderoso, sino la emergencia de un comportamiento errático, monótono, que se sostiene a partir de una mímesis recíproca por parte de un conjunto cada vez más grande de individuos. La incapacidad de la figura del zombi para generar vínculos sociales, para procesar de un modo narrativo su interacción con otros, es complementada por la total incapacidad de la sociedad para articularse y oponer una resistencia real a la epidemia. Como afirma explícitamente el personaje de Francine en Dawn of the Dead, "no es por ellos [que estamos perdidos], sino por nuestra cobardía". La insistente búsqueda de soluciones personales, de preservar la propia seguridad sin atender al destino de la comunidad, es lo que termina en todos los casos por quebrar las posibilidades del grupo social para organizarse frente a la infección.

A su vez, el derrumbe del sistema por la propagación de un deseo de consumo ilimitado que se expresa en Dawn of the Dead (1978), continúa vigente en Day of the Dead incluso cuando el escenario deja de ser un centro comercial para situarse en una base militar. Al retornar a la base en la que un grupo de sobrevivientes se refugia, el piloto del helicóptero afirma que dejaría todo para irse a una isla soleada donde descansar. Ante el reproche de su compañera que le pregunta cómo puede pensar en algo así en la situación que están viviendo, él responde "Podría pensar en eso aunque nada de esto estuviera pasando". Incluso en el marco de un derrumbe del sistema social, lo que motiva las acciones de los sobrevivientes parece seguir atendiendo a los mismos principios que lo generan. La fantasía individual de una vida disipada se presenta como la grieta que da paso una y otra vez a la infección.

Ahora bien, incluso cuando los análisis de Han, Castoriadis y Nietzsche no se proyectan sobre la misma época, existen notables similitudes en sus diagnósticos. Por empezar, la existencia de una condición de esterilidad creciente en los grupos sociales para producir nuevos fenómenos culturales, y a la vez, el vínculo entre esta esterilidad y una creciente fragmentación de la experiencia social. La perspectiva de un gran conjunto de individuos que no logra interactuar entre sí más que a través de una mímesis irreflexiva y que se vuelcan a un consumo compulsivo que no establece relaciones de continuidad o causalidad entre sus diferentes vivencias, esta inevitablemente asociada a la figura de la horda zombi, y coincide con algunas notas centrales del análisis de estos autores. Puede observarse, por consiguiente, la imagen del apocalipsis zombi como una representación con un gran potencial para expresar estos aspectos a la vez que los excesos de la producción actual en su apropiación ilimitada de los recursos naturales. La figura del zombi, como emblema de éstas formas de exceso, encarna la agonía de una sociedad que se agota sobre sí misma. 


\section{Creatividad vs mímesis: representaciones visuales de un tiempo agonizante:}

El argumento del film Day of the Dead ha sido objeto de diversos análisis que coinciden en señalar la expresión de una crítica fuerte a la sociedad disciplinaria, y a los mecanismos de control social. Esta lectura de la obra resulta sugerida por diferentes elementos que conforman la trama, en particular, por tratarse de un pequeño grupo de sobrevivientes conformado por científicos, militares y civiles que se encuentran en una base militar subterránea, y en la que se generan distintos conflictos respecto del modo de organizarse y de subordinarse mutuamente. Pero a su vez, en la medida que la experimentación a la que los científicos someten a los zombis está vinculada a un intento de re-socialización de los mismos a partir de un sistema de premios y castigos que pueda moldear su conducta. ${ }^{29}$ Experimentación que no encuentra ningún límite en cuanto a la violencia física que se requiera impartir sobre los especímenes.

Las imágenes a las que el presente trabajo hará referencia, se presentan sin embargo en los primeros minutos de la obra, antes de que ésta desarrolle los lineamientos generales de la trama.

\section{Primera imagen:}

La primera imagen se trata de una foto rural que aparece en un almanaque en la habitación que comparten dos de los personajes. La importancia de la foto se hace evidente por el lugar que ocupa en la primera escena, sin embargo su sentido o significado dentro de la película no resulta tan claro. A diferencia de la segunda imagen que es producto secuencia de enfoques que narran una situación, la imagen rural del almanaque es una foto impresa, por lo que tendrá diferentes apariciones en el film. En la figura 1 puede verse la imagen en la pared tras uno de los personajes.

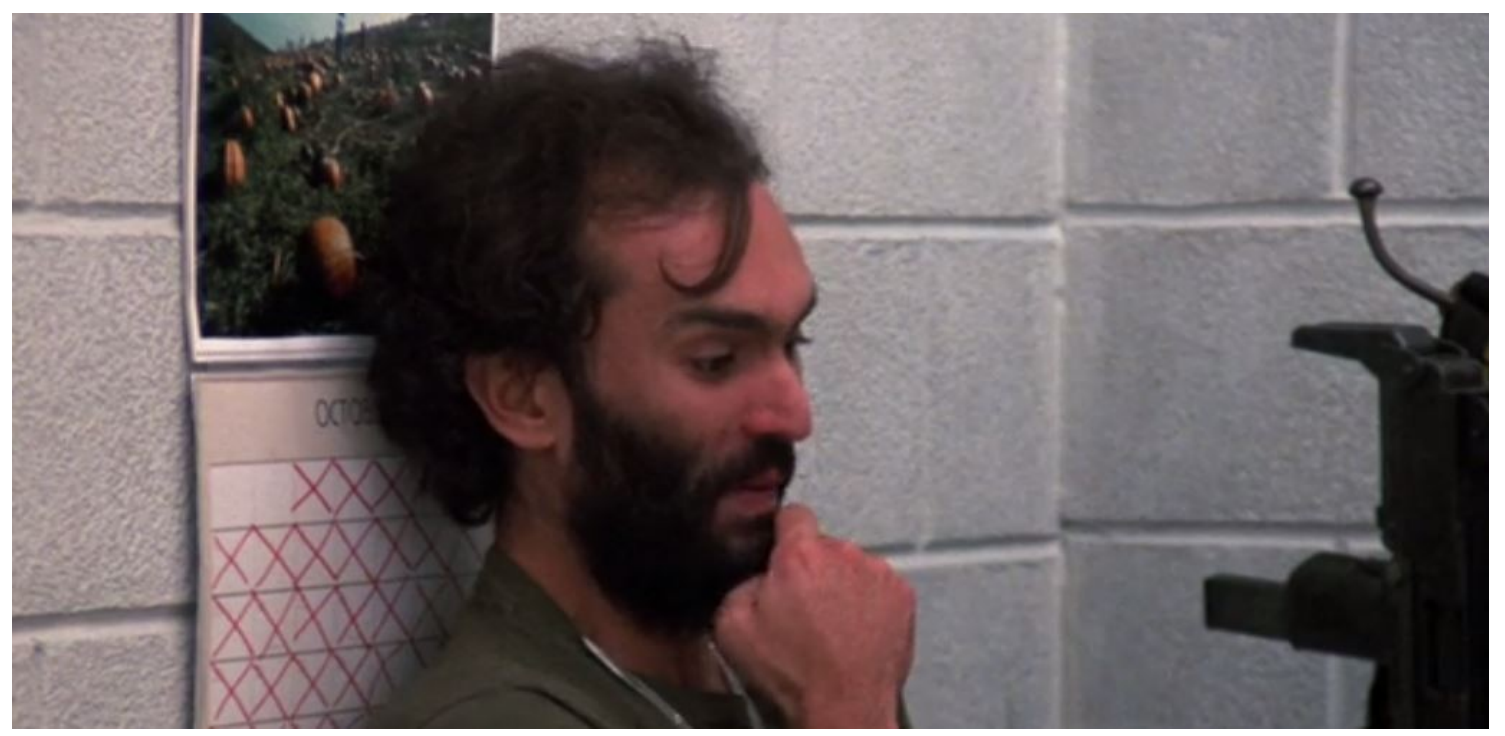

29 En el guión original Romero había previsto que el entrenamiento tuviera finalidades militares, y este aspecto finalmente fue dejado de lado. Sin embargo el único resultado práctico que ofrece el entrenamiento al que se somete al zombi Bud, es que finalmente recuerde o aprenda a usar un arma y la utilice contra uno de los personajes. Las notas de humanidad que logran inscribirse a partir del tratamiento no conducen a otro resultado que una cierta conducta militar, incluso cuando el tratamiento parece ir en una dirección opuesta. 


\section{Figura $1^{30}$}

Ahora bien, la película inicia con una mujer joven que despierta en una habitación totalmente vacía. Frente a ella se encuentra clavado en la pared un almanaque con la imagen de un campo cuyos productos, calabazas de gran tamaño, se encuentran en un punto alto de maduración y puede verse tras ellos a un grupo de hombres trabajando en conjunto. Debajo de la fotografía se encuentran todos los días del mes tachados con cruces bajo el cartel de que indica el mes de octubre. Lo interesante de la imagen es probablemente el modo en que contrasta con la atmósfera general en la que se desarrollarán las situaciones que conforman la trama. Un día soleado, hombres trabajando en armonía, la naturaleza como fuente de abundancia, y la referencia visible a que ese tiempo se ha agotado. Todos esos días han terminado, pero no se inicia un período, no se inicia una nueva hoja detrás del almanaque para volver a registrar el paso del tiempo, sino que se experimenta indefinidamente la subsistencia de ese tiempo agotado.

La reacción ante la imagen por parte de la mujer parece denotar un cierto anhelo, una nostalgia de ese pasado próspero que se interrumpe bruscamente cuando al extender su mano para tocar la foto, la pared es travesada por diferentes manos ensangrentadas que irrumpen simultáneamente en la escena. ${ }^{31}$ Tras el grito del personaje, la escena finaliza y la mujer despierta en un helicóptero.

\section{Segunda imagen:}

El despliegue visual que ofrece la segunda imagen se produce a partir de la serie de elementos que el film propone para formar su contexto. Esto acontece inmediatamente después de la primera escena cuando el helicóptero desciende en una ciudad pequeña y dos sobrevivientes se introducen en una avenida en busca de sobrevivientes. Los diferentes elementos que surgen durante estos primeros minutos serán presentados al espectador mientras uno de los personajes repite la frase "Hello?, Is anyone there?" con un megáfono y pueden recuperarse del siguiente modo:

- Las hojas de las palmeras caídas sin recoger, y signos de descuido que dan cuenta de una naturaleza librada a su suerte. Perspectiva que será reforzada por la presencia de un cocodrilo que se desplaza libremente en la puerta de un banco y por arañas de gran tamaño que caminan sobre un cadáver en una vereda.

- Algunos elementos vuelan en el aire como un grupo de billetes que es movido por un remolino de viento en un rincón de la vereda, o las hojas de un diario que vuelan en la calle y al desplegarse dejan ver la frase "The dead walk!"

Hasta aquí el lenguaje que utiliza Romero puede resultar algo elíptico, pues se advierte que han pasado ya muchos meses desde el colapso del sistema social en el que este tipo de ciudades se organizaban. Esto está claramente denotado por los elementos mencionados al principio, pero luego entra en conflicto con los billetes que giran con el viento, todavía reunidos y limpios, y con las hojas de los diarios que previsiblemente tenderían a deshacerse luego de varias semanas. Estos detalles no parecen accidentales sino que sugieren una referencia a otros elementos que componen la escena.

Por empezar, ambos elementos refuerzan la idea de que la ciudad se encuentra librada a la naturaleza. Los billetes vuelan en el aire sin despertar ningún interés en su entorno, a la vez que el diario anticipa la aparición del primer muerto viviente de la película. Pero al

30 Fotograma de la película Day of the dead (1985) de G. A. Romero.

31 Esta escena ha sido representada en la portada del comic Day of the dead: desertion (2010) de Stef Hutchinson que acompaño la reedición de la película en su 25 aniversario. Sin embargo, la ilustración no incluye el almanaque en la escena. 
mismo tiempo, estos elementos dan una perspectiva muy particular del caos que expresa la ciudad, pues en éste caos, en esa vuelta al orden natural, los diarios permanecen exhibiendo la misma noticia, el dinero aunque librado al viento sigue limpio y reunido, animales peligrosos se paran en la puerta de los bancos. No parece la forma de un caos, ni de un apocalipsis, sino más bien la presentación de una nueva naturaleza con su propia entropía, o inclusive de la misma naturaleza a la que estaba librada la ciudad antes de la infección, en definitiva, una presentación de la ciudad que sólo busca mostrar un reflejo deformado de la ciudad real, del funcionamiento normal de una ciudad occidental.

Es importante señalar, pese al deterioro que se observa en la ciudad, el escenario que muestra Romero puede ser interpretado en términos de una excesiva permanencia, antes que como una representación del derrumbe del sistema. Una permanencia que lejos de entrar en crisis, se presenta como una lenta y tardía descomposición que no permite la emergencia de un estado de crisis. El zombi, en su enigmático subsistir a la muerte, encarna individual y colectivamente el sentido de esta permanencia, de éste lastre del pasado que no permite la emergencia de un presente articulado que pueda expresarse como un polo creativo. En un sentido general, puede decirse siguiendo a Edgar Morin, que ésta es la operación misma que se encuentra en el centro del cine como fenómeno estético, pues las imágenes captadas por la cámara eternizan la realidad al mismo tiempo que, como parte de esa misma conservación, las vampiriza, les extrae todo lo que tienen de vital. El resultado paradójico de esta operación es que el cine destruye aquello que preserva, (Morin, 2001; Esposito, 2015) y lo que el escenario que propone Romero expresa es la decadencia de esa misma permanencia. La permanencia de una estructura que se agota sobre una repetición que paradójicamente comienza a desgastarla.

Tras la aparición de estos elementos, se presenta el primer zombi de la película. El llamado del altavoz que el personaje de Miguel realiza insistentemente no parece encontrar un interlocutor adecuado. Aquí el registro de Romero se vuelve irónico, pues el cuerpo que se acerca caminando y que culmina en un primer plano, corresponde a un hombre mayor cuya mandíbula inferior se encuentra notablemente dañada, o simplemente ausente, y cuya lengua cae por su cuello a medida que avanza. La pregunta "Is anyone there?" trae a escena un personaje que en principio, no puede contestar al llamado. El mutismo es lo que configura aquí al zombi como una otredad radical, aquello con lo que no puede establecer ningún tipo de intercambio, que sin importar los medios expresivos que se utilicen no logra reconocernos como sujetos, ni reconocer otros zombis. (Fernández, 2011: 77)

Es entonces cuando el cartel de "Day of the Dead" aparece frente al zombi, y comienzan a aparecer una serie de elementos que denotan cierta ironía: el vendedor de entradas de cine tiene un ojo mutilado, dos zombis obesos salen por la puerta del banco, y aparecen diferentes zombis que encarnan estereotipos muy definidos de personas que habitaran la ciudad en un tiempo pasado. La horda que lentamente comienza a formarse y a ordenarse en torno de la avenida, ofrece la perspectiva de una armonización de las diferencias de clase que suele presentar en las representaciones de Romero.

La horda que avanza por la avenida en dirección a los sobrevivientes pasa a ser contemplada finalmente desde las afueras de la ciudad, el personaje de Miguel huye mientras que Sara permanece observando un momento más, dando lugar a la segunda imagen que se quiere recuperar.

Efectivamente esta imagen se identifica con la perspectiva de la ciudad desbordada por la infección que amenaza al espectador. Todas las edificaciones, los autos que rodean ambas veredas y cuyas puertas se encuentran abiertas en algunos casos, los carteles comerciales, el tendido eléctrico, todos estos elementos se encuentran inutilizables, pues ninguno de ellos alcanzaría a proteger a los sobrevivientes del grupo de zombis que se acerca, que sólo invita a los personajes a escapar o refugiarse. Lo único que se muestra como capaz de poner en movimiento a la ciudad es la llegada de individuos extraños que 
rompen la excesiva armonización de las expectativas recíprocas que envuelve a los individuos que se masifican en la horda. Lo potencialmente diferente debe ser eliminado, $o$ consumido para poder retornar a ese estado previsibilidad absoluta. La otredad no puede ser experimentada, ni siquiera confrontada, sino consumida.

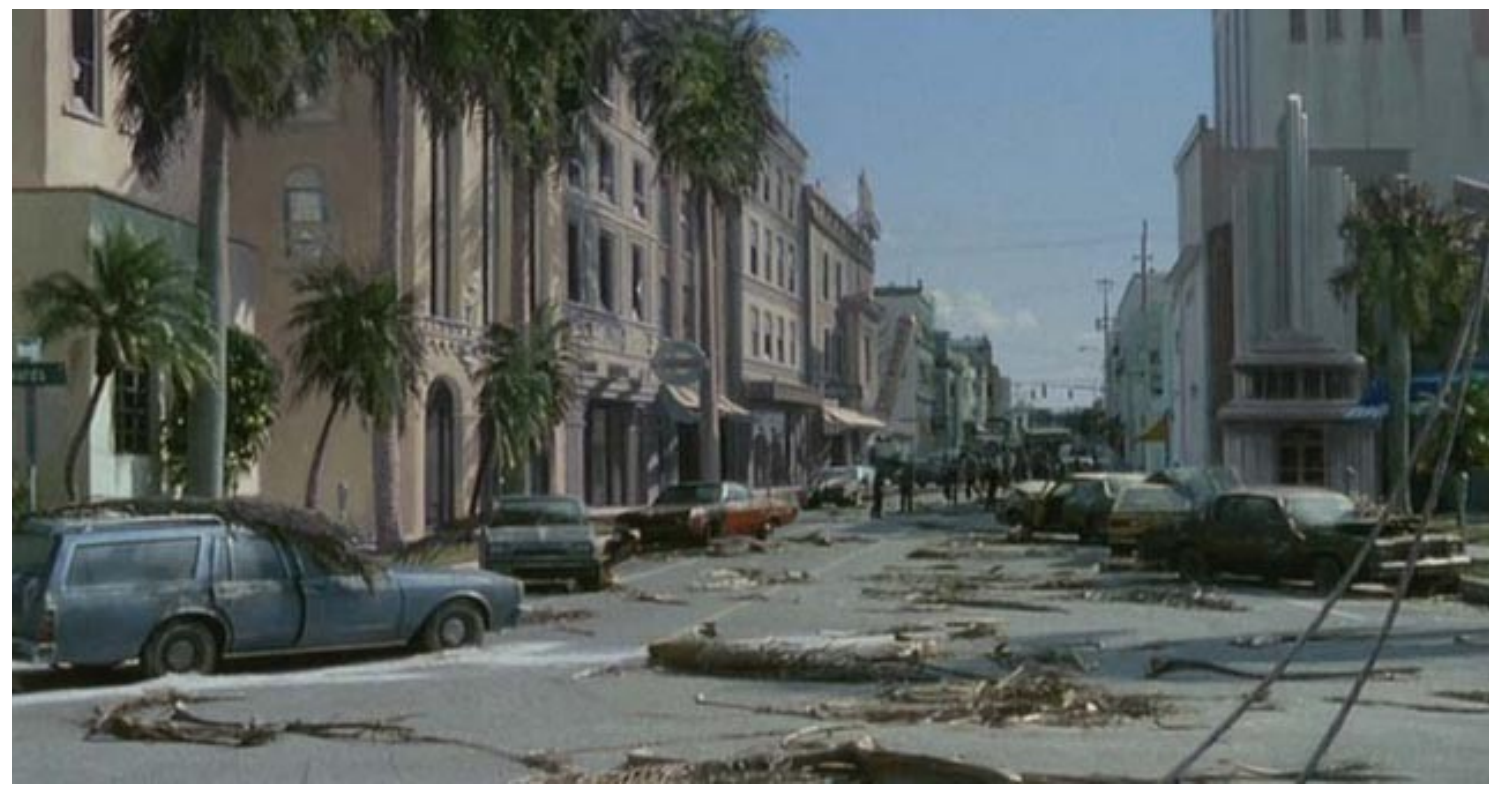

Figura $2^{32}$

Es interesante observar como la dinámica que muestra la escena reproduce con precisión aquello que Han describe como el avance de la identidad de lo igual sobre la posibilidad de que emerja lo diferente, donde la identidad, a fin de neutralizar el contacto con lo extranjero, traduce la extrañeza de lo Otro a la figura de lo exótico, de manera que no resulta inquietante sino un simple objeto de consumo. (Han, 2015a: 17) La aparición de algo nuevo en la esfera social, representada por la llegada de los sobrevivientes, se traduce en la figura neutralizada de la novedad que puede ser consumida, que puede ser deseada como objeto. "Todo es aplanado para convertirse en objeto de consumo." (Han, 2015b:11) El vínculo de amistad o de eros entre los hombres se reduce así a un vínculo de consumo y permanencia, de repetición de lo mismo y traducción de lo nuevo en lo mismo. "En el infierno de lo igual - afirma Han - la llegada del otro atópico puede asumir una forma apocalíptica” (Han, 2015b: 12)

En este sentido, la imagen de la avenida muestra a su vez la perspectiva de un sistema cerrado a partir de la intromisión de individuos que están de una u otra manera fuera del sistema. Todo cuanto ven los sobrevivientes parece un recurso, pero respondiendo a una tendencia casi natural los individuos que reaccionan ante su presencia se organizan en torno de la supresión de esta intromisión. La actitud de los sobrevivientes parece responder a un cierto altruismo al buscar rescatar a más personas, pero esto no tiene lugar dentro de una forma de organización espontánea que muestran los zombis en la que, sin necesidad de coerción, se tiende al consumo de la novedad y la eliminación de su potencial para alterar el orden. Los individuos se reúnen espontáneamente para defender un sistema que no entienden, y esta defensa no alcanza la forma de una ofensiva sino de una compulsión al consumo. Aquí la metáfora romeriana del consumo mediante la ingesta misma del cuerpo de los personajes se muestra algo grotesca frente a otras formas de representación, pero su potencial crítico parece intacto, pues incluso cuando la emergencia de la infección constituye el derrumbe del sistema vigente, y la presentación de una forma

32 Fotograma de la película Day of the dead (1985) de G. A. Romero. 
de carnavalización de la sociedad actual (Coulombe, 2012: 98-101), una vez que se ha propagado, una vez que los sobrevivientes sólo pueden recluirse en lugares apartados, la horda se presenta como una multitud normalizada que asegura y efectiviza la permanencia de una forma de asociación que se cierra y clausura sobre su presente, hasta agotarse en él. No se abre un espacio de indefinición, sino que la ruptura del sistema y su carnavalización devienen en una permanencia decadente. En eso consiste precisamente el vínculo estrecho que la figura del zombi establece con el apocalipsis.

El avance de la infección tiende a mostrarse como exponencial e imposible de detener, pero al mismo tiempo, la horda de zombis, como figura que heredaría la tierra, constituye un apocalipsis en sí mismo, pues no se presenta como una forma de comunidad que pueda continuarse en el tiempo. La infección puede expandirse, puede aniquilar o transformar todo a su paso, pero no puede permanecer. El único fruto de su conducta es el incremento cuantitativo y territorial del grupo, pero el destino de su expansión consiste en un lento pero inevitable proceso de descomposición. ${ }^{33} \mathrm{El} \mathrm{zombi,} \mathrm{como} \mathrm{figura} \mathrm{que} \mathrm{busca} \mathrm{representar}$ este estado de agotamiento, se proyecta por consiguiente sobre los aspectos más paradojales de modelo de consumo y crecimiento ilimitado de las sociedades occidentales actuales.

De este modo, quedan enmarcadas ambas imágenes y las significaciones principales a las que pueden ser asociadas, pero resta todavía observar las formas de subjetividad a las que remiten, y la forma de interacción con el medio que suponen.

\section{Fenomenología del zombi y los principios de su conducta:}

Ahora bien, como se observa los contextos que muestran ambas imágenes ofrecen posibilidades a los individuos que las habitan. El contexto rural se presenta una fuente de recursos de los que los hombres pueden agenciarse para generar objetos que cubran sus necesidades, mientras que el segundo contexto, como versión consumada y excesiva de tal apropiación, no ofrece nada a los individuos. Los dos personajes que observan la ciudad sólo pueden ser espectadores de tal decadencia, y nada hay en ella que pueda ser agenciado, pues lo único susceptible de ser un objeto de consumo son los mismos personajes que están observando la avenida. La cosificación del otro y la neutralización de su potencial alteridad se expresa de un modo notablemente claro en la escena.

Ciertamente, puede resultar conveniente abandonar la perspectiva de los sobrevivientes en la segunda imagen para explorar la perspectiva de los integrantes de la horda. Es notable en este sentido que la perspectiva de quien capta la primera imagen no es marcadamente diferente que la de los individuos que aparecen en ella, mientras que la segunda imagen sólo puede ser captada por un espectador radicalmente distinto a los individuos que la integran, y es precisamente la presencia de este espectador lo que origina la imagen, pues lo que los elementos que la anticipan parecen mostrar es que el movimiento en la ciudad sólo se produce a partir de su aparición.

Como afirma Fernández Gonzalo el zombi es un individuo se caracteriza por su falta de interioridad. Sin embargo, autores como Coulombe intentan explorar el mundo interior del zombi, y los lineamiento generales que organizan su conducta. En esta caracterización, Coulombe observa que la conducta general que muestran los muertos vivientes puede asimilarse a la de un hombre traumatizado. La imagen general que interesa al autor es la del zombi como el reflejo deformado del hombre común. Aquello que el hombre no quiere ver de sí mismo, pero que representa un destino posible. (Coulombe, 2012: 53-63)

33 Éste aspecto es captado con claridad en el film 28 Days Later (2002) de Danny Boyle, cuando el personaje del Comandante Henry West afirma sobre uno de los infectados "me dice que nunca cocinará un pastel, ni plantara un árbol, ni criará vacas. Me dice que no tiene futuro.” 
Las dos actitudes que Coulombe destaca son: por un lado, la actitud nostálgica que el zombi presenta cuando se encuentra solo, en la que se vuelca torpe y reiterativamente a determinados hábitos de la vida pasada, y por otro lado, la actitud violenta e irreflexiva con la que avanza hacia sus víctimas. En esta segunda conducta se observan las tendencias que se han mencionado a lo largo del trabajo: la masificación indiferenciada, la imposibilidad de reconocer a los hombres más que como meros objetos, la necesidad de una ingesta ilimitada, la reducción a un comportamiento monótono y violento, y en fin, la conducta torpe pero insistente que caracteriza a esta figura. Sin embargo, la fuerte influencia de la mímesis recíproca de los zombis no parece ser captada en el análisis de Coulombe, y es una conducta que no se produce cuando el zombi se encuentra en soledad ni cuando se incorporado a la horda, sino que se muestra precisamente en la conformación de la horda, y en la reacción de los zombis al ver que otros zombis se dirigen en una dirección.

En efecto, tal como menciona Fernández Gonzalo, la interacción entre los muertos vivientes no es tal que éstos formen un grupo real, sino una mera reunión sin líder ni jerarquías internas. Sin embargo, esto es discutible en el cine de Romero a partir de dos elementos:

a) Por un lado, los zombis tienden a agolparse donde otros zombis ya se encuentran o caminar hacia donde los otros caminan. Esto es explicado con gran detalle por Robert Kirkman en el comic The Walking Dead $\mathrm{n}^{\circ} 54$ cuando uno de los personajes explica con gran detalle el modo en que distintos grupos de zombis se encuentran y van formando un grupo cada vez mayor, habiendo olvidado ya el motivo inicial de su movimiento. La importancia de la mímesis en la conducta del zombi, incluso cuando se limite a "ir a donde los otros van" resulta en verdad un aspecto central, pues por un lado, constituye su mayor peligro, ya que es el único mecanismo por el que tiende a formar grupos que puedan representar un riesgo real, y a su vez, en tanto que denuncia el peligro de las tendencias de la moda, la masificación irreflexiva de los individuos, y en definitiva, la institución de la mímesis como conducta social central.

b) Por otro lado, la falta de jerarquía en la horda no es tan clara en el cine de Romero. Más bien, puede interpretarse el desarrollo de las primeras cuatro películas en el sentido de la emergencia de un líder. En la primera obra, The night of the living Dead, el problema del liderazgo se presenta entre los sobrevivientes que están dentro de la casa, sin embargo, la aparición del hermano reanimado de uno de los personajes termina por vulnerar en cierto sentido sus defensas, pues su hermana Barbara no puede evitar ir hacia él. En su segundo film, Dawn of the Dead, es uno de los sobrevivientes quien, al volverse zombi, guía a la horda contra una falsa pared y termina conduciéndolos al escondite de sus compañeros, encabezando al grupo.

En Day of the Dead, la transformación de Bud, a partir de un cruento tratamiento, en un zombi con capacidad de manejar un arma, y de tener fines diferentes de la mera ingesta de carne, posee un mayor grado de desarrollo. El resultado final es un zombi que pudiera erigirse como líder de la horda, pero la película no desarrolla tal posibilidad ni la plantea de un modo explícito. Será en 2005 cuando se presente Land of the Dead, donde está posibilidad se desarrolle al máximo. Aún con los 20 años que separan la tercera de la cuarta película, Romero retoma la evolución de un liderazgo en la horda en el mismo punto en el que la había dejado planteada en el film de 1985. Sólo que en la última de las cuatro obras iniciales éste liderazgo será capaz de guiar a los zombis hasta la ciudad en la que se encuentran los hombres que les disparan y los saquean permanentemente. La posibilidad de liderazgo que dejan entrever las obras de Romero sólo se apoya en la mímesis recíproca de los zombis, y en la posibilidad de direccionar esa imitación. 


\section{Reflexiones finales:}

A partir de lo desarrollado en el trabajo puede recuperarse el valor crítico del cine de Romero si se establece una lectura que entre en diálogo con los diagnósticos que distintas corrientes intelectuales establecen sobre los fenómenos sociales actuales. Y a su vez, señalar el potencial crítico de las primeras imágenes que se presentan en Day of the Dead y que han sido analizadas en el trabajo. La recuperación de la tendencia a la mímesis como único impulso social que expresa la figura del zombi y que le permite formar grupos que puedan potencialmente transformar lo diferente en igual, confrontar cualquier posibilidad de que emerjan nuevos vínculos y significaciones, representa probablemente el principal aspecto que se ha querido señalar en el trabajo, pues resuenan en esta dinámica los diagnósticos de pensadores como Cornelius Castoriadis, al afirmar que las sociedades occidentales se encuentran en un estado de heteronomía en el que la repetición institucional confronta la posibilidad de que emerja la alteridad, entendida como producto creativo de los hombres. A la vez que pueden percibirse algunos elementos del diagnóstico que establece Byung-Chul Han, en relación al predomino del Yo sobre el potencial transformador del contacto con la Otredad, y a la fragmentación de la experiencia social. Y por último, ésta dinámica puede observarse también en algunas notas de la crítica de Nietzsche a la modernidad y su diagnóstico general sobre la dificultad de los hombres de generar cultura a partir de la ruptura del marco de sentido que el pensamiento mítico ofrecía al mundo cultural.

La relevancia que reviste la comprensión de las significaciones a las que la temática está asociada es reforzada a su vez por el gran número de producciones que se están llevando a cabo en diferentes medios expresivos y por la diversidad de significaciones a las que se asocian. Así, mientras que en películas como Land of the Dead los zombis se presentan como una clase social oprimida y vulnerable, en películas como Guerra mundial $Z$ (2013), La horde (2009) o Juan de los muertos (2011) el zombi parece asociarse a la temática de la inmigración, en otras como la película coreana Miss Zombie (2013) o Fido (2006) el vínculo entre los hombres y los zombis reproduce la dialéctica del amo y el esclavo de Hegel, y esto se presenta de diferentes maneras en otras representaciones.

La posibilidad de hacer un trabajo de análisis de los elementos que estas representaciones ofrecen permite por tanto generar una aproximación diferente de nuestra actualidad, a partir de la comprensión productos culturales que buscan reflejar y caricaturizar distintos elementos del presente, expresando el agotamiento o el callejón sin salida de las tendencias actuales si se las proyecta hacia el futuro. El carácter apocalíptico del cine romeriano no parece ofrecer ya la perspectiva de una sociedad de control y disciplinaria que puede encontrarse en películas como Brazil (1985) o Rollerball (1975), sino la perspectiva de una sociedad que se desarticula gradualmente en una permanencia decadente, consumida en su propia reiteración.

El optimismo que se percibe en el final que presenta la película, puede resultar algo ambiguo, en la medida que parece repetir las condiciones iniciales de Dawn of the Dead, pero quizá se presente realmente como un desenlace agradable para los personajes, pues el personaje de Sara comienza a marcar nuevamente los días en el almanaque, y el tiempo comienza a avanzar. La idea expresada por el piloto del helicóptero de abandonar toda la información que estaba guardada en la base militar y "nunca más volver por ella" se hace efectiva en la última escena en la que tres de los personajes llegan a una isla desierta y tratan de establecer un nuevo comienzo. La película que concluye lo que se ha dado a llamar la trilogía original de Romero, prescribe de algún modo un abandono de la búsqueda de una salida dentro de la ciudad, incluso dentro de un refugio como se intenta inútilmente en las tres películas, para establecer un reencuentro con la naturaleza, en el retorno a la apropiación artesanal de los recursos naturales. Éste último aspecto constituye 
sin duda el único elemento en el apocalipsis romeriano que permite albergar una esperanza sobre el futuro y que a la vez termina de subrayar y dar significado al contraste entre las dos imágenes que se recuperan en el principio del film y que han sido analizadas en el trabajo.

\section{Bibliografía:}

CASTORIADIS C., (2006a) "Antropogenia en Esquilo y autocreación del hombre en Sófocles” en: Figuras de lo pensable, Bs. As., Fondo de Cultura Económica

----, (2006b) "Imaginario e imaginación en la encrucijada" en: Figuras de lo pensable, Bs. As., Fondo de Cultura Económica.

----, (2007a) “La crise des sociétés occidentales ” en: La montée de l'insignifiance, Paris, Seuil.

----, (2008) “La época del conformismo generalizado", en: El mundo fragmentado, La Plata Terramar.

CASTORIADIS C. Y LASCH C., (2013) La culture de l'égoïsme, Lonrai, Climats.

COULOMBE M., (2012) La petite philosophie du zombie, Paris, PUF.

DÍAZ D.P., (2010) La ontología de la historia de Nietzsche, Universidad Complutence de Madrid.

ESPOSITO R., (2015) “Abrir un horizonte sobre aquello que es negado", en: Cine y Filosofía. Las entrevistas de Fata Morgana, Bs. As., El cuenco de plata.

FERNÁNDEZ A., (1985) "El cine y la investigación en ciencias sociales" en: Cine antropología y colonialismo, Bs. As., Ediciones del Sol (CLACSO).

FERNÁNDEZ J.G., (2011) Filosofía zombi. Barcelona, Anagrama.

----, (2012) “¿Apocalipsis o apoca-e-lipsis? Pantalla y emociones en The Walking

Dead." en: The Walking Dead. Apocalipsis zombi ya. Madrid, Errata Naturae.

HAN Byung-Chul, (2015a) La sociedad del Cansancio, Bs. As. Herder.

----, (2015b) La sociedad de la transprencia, Bs. As., Herder.

----, (2015c) La agonía de Eros, Bs. As., Herder.

----, (2015d) Piscopolítica, Bs. As. Herder.

IMBERT G., (2010) Cine e imaginarios sociales, Madrid, Cátedra.

KIRKMAN R., (2008) The Walking Dead. $\mathrm{N}^{\circ} 54$, USA, Image Comic.

LUCENA J. M., (2012) Ensayo Z. Antropología de la carne perecedera. España. Editorial Berenice.

MORIN E., (2001) El cine o el hombre imaginario, Barcelona, Paidós.

NIETZSCHE F., "Sobre la utilidad y el perjuicio de la historia para la vida", en: Obras completas vol. I, Madrid, Gredos. 2010.

PARIS V., (2013) Zombies. Sociologie des morts-vivants. Quebec, XYZ Édition.

RANCIËRE J., El espectador emancipado, Bs. As., Ediciones Manantial, 2008.

SARTRE J.P., (2004) "La desmilitarización de la cultura", en Problemas del marxismo, Bs. As., Losada.

\section{Filmografía:}

28 Days Later (D. Boyle, 2002)

Brazil (T. Gilliam, 1985)

Dawn of the Dead (G. A. Romero, 1978).

Day of the Dead (G. A. Romero, 1985).

Diary of the Dead (G. A. Romero, 2007).

Fido (A. Currie, 2006) 
Guerra mundial $Z$ (M. Foster, 2013)

Juan de los muertos (A. Brugués, 2011)

La horde (Y. Dahan y B. Rocher, 2009)

Land of the Dead (G. A. Romero, 2005).

Miss Zombie (H. Tanaka, 2013)

Rollerball (N. Jewison, 1975)

Survival of the Dead (G. A. Romero, 2009)

The night of the living dead (G. A. Romero, 1968).

The night of the living dead (G. A. Romero, 1990). 